\title{
LA RESPONSABILIDAD DE LOS REPRESENTANTES FRENTE A SUS ELECTORES EN COLOMBIA
}

\author{
SERGIO ORLANDO SILVA ARROYAVE
}

(C) UNED. Revista de Derecho Politico

N.o 111, mayo-agosto 2021 
SUMARIO

INTRODUCCIÓN. I. LA RESPONSABILIDAD DE LOS REPRESENTANTES EN LOS REGÍMENES REPRESENTATIVOS. I.A. La aparición del Régimen Representativo. I.B. Las obligaciones de los Representantes en el Régimen Representativo. II. LAS OBLIGACIONES DE LOS REPRESENTANTES EN COLOMBIA. II.A. El Régimen Representativo en Colombia. II.B. El reducido control sobre los Representantes en Colombia. CONCLUSIÓN. BIBLIOGRAFÍA. 


\title{
LA RESPONSABILIDAD DE LOS REPRESENTANTES FRENTE A SUS ELECTORES EN COLOMBIA
}

\author{
SERGIO ORLANDO SILVA ARROYAVE ${ }^{1}$ \\ Facultad de Derecho y Ciencias Forenses, Tecnológico de Antioquia
}

\section{INTRODUCCIÓN}

Cualquiera que estudie la responsabilidad en la política, pronto descubrirá que puede significar muchas cosas diferentes. Esto se debe, en gran parte, a que el concepto de responsabilidad suele utilizarse como sinónimo de varios otros conceptos utilizados en la política, como los de buen gobierno, transparencia, equidad, democracia, eficiencia, capacidad de respuesta o integridad ${ }^{2}$.

Sin embargo, teniendo en cuenta varios de estos conceptos, la doctrina ha podido precisar los elementos esenciales que configuran la responsabilidad de los funcionarios públicos. De esta manera, se identificó que la responsabilidad exige necesariamente la existencia de un castigo ${ }^{3}$, pero no se reduce a este solo elemento. Así, la responsabilidad implica además ${ }^{4}$ «la obligación de los servidores públicos para informar y explicar qué están haciendo» ${ }^{5}$, en un lenguaje comprensible por los ciudadanos y la capacidad de las instituciones de control para imponer sanciones a los «detentadores del poder, quienes hayan violado sus responsabilidades públicas» ${ }^{6}$.

No obstante, para que la información permita sancionar a los funcionarios públicos infractores, no solamente se requiere que estos permitan el acceso a la información

1 Doctor en derecho de la Université Panthéon-Assas (Paris II). Profesor titular de Derecho Constitucional, Facultad de Derecho y Ciencias Forenses, Tecnológico de Antioquia, Calle 78B \# 72A - 220 Medellín - Colombia. E-mail: sosilva694@yahoo.es. Las citas de referencias en lengua extranjera fueron traducidas por el autor.

2 Bovens, M. (2010), «Two Concepts of Accountability: Accountability as A Virtue and as A Mechanism», West European Politics, Vol. 33, num. 5, p. 946

3 Behn, R. (2001), Rethinking Democratic Accountability, Washington, Brookings Institution, p. 3

4 Schedler, A. (2004), ¿Que es la rendición de cuentas? México, IFAI, p. 14

5 Ackerman, J. (2006), «Sociedad civil y rendición de cuentas», en Ackerman, J. et al, Elecciones y ciudadanía en el distrito federal, México, IEDF, p. 14

6 Ibidem, p. 15 
contable. Lo que se requiere es que «los servidores públicos deban informar activamente y, en su caso, explicar y justificar lo que están haciendo en un lenguaje comprensible y accesible a los ciudadanos» ${ }^{7}$.

Algunos autores han afirmado que la responsabilidad solo existe para los funcionarios públicos cuando estos deben informar sus actos a sus superiores jerárquicos y pueden ser sancionados por ellos ${ }^{8}$. Sin embargo, este elemento no parece ser un criterio esencial, puesto que no solo existe el control jerarquizado, sino también el control interno y horizontal, cuando por ejemplo los servidores públicos se vigilan entre ellos mismos. De esta manera, no se debe «confundir el poder de sancionar con la naturaleza de ser una autoridad superior. El hecho de que alguien pueda castigar no implica necesariamente que ese alguien ostente una cualidad de superioridad jerárquica respecto al actor amonestado» ${ }^{9}$. Aunque, para que el control sea mas eficiente se recomienda que las explicaciones y justificaciones se entreguen a los ciudadanos y a las demás autoridades que no hagan parte de la misma dependencia, con la finalidad que exista un control desde el exterior.

Es común que la responsabilidad de los funcionarios públicos sea analizada al final de su gestión. Sin embargo, la responsabilidad puede analizarse «ex-post para referirse a la evaluación de proyectos terminados, [...] ex-ante para referirse a la evaluación de planes de acción, y [... de manera $]$ simultánea, para referirse a la evaluación de iniciativas gubernamentales en curso ${ }^{10}$. Es así, como la responsabilidad de los funcionarios públicos debe analizarse de manera dinámica, teniendo en cuenta el interés que tienen para informar claramente en todo momento de sus gestiones y para adecuar sus decisiones, según las necesidades y los intereses reales de los ciudadanos.

En definitiva, es así, como de una manera amplia, la responsabilidad de los funcionarios públicos puede definirse como un «proceso proactivo por medio del cual los servidores públicos informan y justifican sus planes de acción, su desempeño y sus $\log$ ros y se sujetan a las sanciones y las recompensas correspondientes ${ }^{11}$.

Sin embargo, muchos de los autores que adoptan esta concepción de la responsabilidad de los funcionarios públicos, construida en las últimas décadas ${ }^{12}$, se centran solamente en los deberes de información que deben cumplir estos funcionarios luego de que tomaron sus decisiones o incluso empezaron a actuar en su desarrollo y en las sanciones o recompensas que les pueden generar su gestión. Pero, dejan de lado algunas ideas mas antiguas que analizan cual debe ser el origen de las decisiones políticas

Ibídem, p. 15

8 Moreno, E., Crisp, B. y Shugart, M. (2003), «The Accountability Deficit in Latin America», en Mainwaring, S. y Welna, Ch. (eds.), Democratic Accountability in Latin America, Nueva York, Oxford University Press, pp. 79-131

9 Ackerman, J. (2006), «Sociedad civil y rendición de cuentas»... cit, p. 17

10 Ibidem, p. 18

11 Ibidem, p. 12

12 Mulgan, R. (2000). «Accountability: An Ever Expanding Concept?», Public Administration, Vol. 78, num. 3, p. 555 
en los cuerpos colegiados de representación, si los Representantes deben escuchar a sus electores o a los ciudadanos en general al momento de votar o de definir sus planes de acción o si ellos tienen la obligación de cumplir con sus propuestas de campaña.

El análisis de estos últimos elementos es esencial, puesto que antes de identificarse como los Representantes deben rendir la información y como sancionarlos, se debe tener claro cuales son las obligaciones que deben respetar al momento de decidir, para que así los ciudadanos puedan luego informarse de esa decisión y sancionarlos, si no están de acuerdo. Es así, como la responsabilidad de los Representantes está íntimamente ligada a la forma de gobierno existente en el Estado, puesto que en una dictadura el tirano no estaría obligado a decidir según la voluntad del pueblo y de nada serviría que el pueblo se diera cuenta de sus decisiones, puesto que no podría en ningún caso sancionarlo.

El estudio de la responsabilidad de los Representantes frente a sus electores es particularmente importante en América Latina, puesto que estos países, además de contar con altos niveles de corrupción y de poca transparencia en la administración pública $^{13}$ y de poseer amplias falencias en la democracia ${ }^{14}$, siguen estando afectados por la «escasez de estudios que analicen específicamente el vínculo a partir del cual los ciudadanos delegan la capacidad de formular decisiones políticas en sus gobernantes, estructurando así, mecanismos de representación» ${ }^{15}$.

En el caso colombiano en particular, no se han hecho muchos estudios que se centren en la identificación precisa de la relación existente entre los Representantes en los cuerpos colegiados y sus electores o en la definición de las obligaciones que los

13 En el último índice de percepción de la corrupción realizado por Transparencia Internacional (2019), la mayoría de los países de la región, con la excepción de Chile, Costa rica y Uruguay, tuvieron una calificación interior a 50/100.

14 En el Índice de Democracia del año 2019, elaborado por la Revista The Economist, la mayoría de los países de la región, con la excepción de Chile, Costa rica y Uruguay, fueron calificados como democracias defectuosas (Flawed democracies), porque son países en los cuales se realizan «elecciones libres y justas, y aunque tienen problemas (como las infracciones a la libertad de los medios de comunicación), se respetan las libertades civiles básicas. Sin embargo, existen importantes debilidades en otros aspectos de la democracia, como problemas de gobierno, una cultura política subdesarrollada y bajos niveles de participación política». The Economist (2019), Democracy Index 2019, p. 53, en: https://www.eiu.com/ topic/democracy-index

15 Luna, J. (2007), «Representación política en América Latina, el estado de la cuestión y una propuesta de agenda», Política y gobierno, vol. XIV, núm. 2, p. 393. Aunque, se ha hecho grandes avances. Ver, por ejemplo: Cansino, C. y Covarrubias, I. (eds.), (2007), Por una democracia de calidad. México después de la alternancia. México, Cepcom, Educación y Cultura; Garrido, A., Martínez, M. y Parra, F. (2011), Accountability, democracia y reforma política en México, México, Siglo XXI; Morlino, L. (2012), «Observando las diferentes calidades de la democracia», Revista Mexicana de Análisis Político y Administración Pública, Vol. 1, núm. 1, pp. 9-48 y Cantú, G. (2019), «Responsividad democrática. Distintas aproximaciones a un concepto con un amplio potencial», Política y gobierno, vol. XXVI, núm. 2, pp. 237-259.

N. ${ }^{\circ} 111$, mayo-agosto 2021, págs. 315-342 
primeros tienen frente a los segundos al momento de tomar sus decisiones o de participar en la aprobación de una norma ${ }^{16}$.

La identificación de las obligaciones que actualmente tienen los Representantes en Colombia al momento de tomar sus decisiones es una cuestión compleja, puesto que, aunque se afirma comúnmente que Colombia es una democracia, no se conoce con precisión cuales son las obligaciones de los Representantes según la manera como esta reglamentada esta forma de gobierno en este país. De manera general, esta dificultad se presenta por cuanto «en el lenguaje corriente como en el filosófico, puede hablarse de "democracia" para referirse tanto a un ideal como a regímenes reales que están muy lejos de cumplir con ese ideal» ${ }^{17}$.

En realidad, si se analizan los criterios esenciales tenidos en cuenta por los principales pensadores que durante el siglo XVIII y principios del siglo XIX fijaron las bases de los Estados actuales, tendríamos que decir que para estos autores estos Estados no eran democracias. Esto se debe a que los principales teóricos de los Estados occidentales actuales conceptualizaron una forma de gobierno diferente que denominaron «Régimen Representativo», el cual se diferenciaba claramente de la democracia, puesto que «en la primera, la nación delega el ejercicio de la soberanía en las autoridades elegidas, mientras que, en la segunda, el pueblo ejerce el mismo su soberanía» ${ }^{18}$.

Estas ideas ampliamente conocidas en Europa, han sido bastante ignoradas por la doctrina colombiana. Por esta razón, la comprensión del Régimen Representativo es esencial, porque sus postulados siguen teniendo vigencia hoy en día y son los que definen las obligaciones de los Representantes al momento de tomar sus decisiones. De esta forma, se hace necesario revisar los postulados del Régimen Representativo, puesto que solo de esta manera, se podrá entender mejor la forma de gobierno existente en Colombia y se podrá identificar precisamente cuales son las responsabilidades de los Representantes frente a sus electores, cuales son los deberes que deben cumplir los ciudadanos luego de la elección para vigilar el ejercicio del poder por sus Representantes, y sobre todo, se podrá identificar cuales son las modificaciones que deben adoptarse para el fortalecimiento de las relaciones entre los Representantes y los electores en Colombia. Para ello, se analizará en un primer momento, la responsabilidad de los Representantes en los Regímenes Representativos (I), para luego analizar, en un segundo momento, las obligaciones de los Representantes en Colombia (II).

16 Se ha hecho un estudio en general sobre los países Andinos. Ver: Mainwaring, S., Bejarano, A., y Pizarro, E. (eds.) (2008). La crisis de la representación democrática en los países andinos, Bogotá, Norma.

17 Dahl, R. (2002), La Democracia y sus críticos, Barcelona, Paidós, p. 15

18 Brunet, P. (2012), «La Représentation», en Troper, M. y Changollaud, D., Traité international de droit constitutionnel, Tome I : Théorie de la Constitution, Paris, Dalloz, p. 610 


\section{LA RESPONSABILIDAD DE LOS REPRESENTANTES EN LOS REGÍMENES REPRESENTATIVOS}

Desde hace muchos siglos, varias formas de gobierno se han servido de la figura de los Representantes para organizar la manera como los diferentes órganos del Estado cumplen con sus competencias. De esta manera, en la democracia directa practicada en la antigua Atenas o en los parlamentos medievales, existieron Representantes para la ejecución de ciertas funciones públicas. Sin embargo, la responsabilidad de los Representantes frente a los electores ha cambiado bastante a través de la historia según la forma de gobierno puesta en práctica en los Estados.

Para entender estos cambios en la responsabilidad, debe distinguirse entre la responsabilidad jurídica y la responsabilidad política de los Representantes. Por la primera, el incumplimiento de las obligaciones de los Representantes les acarrea unas sanciones previamente definidas en la ley, como la suspensión en el ejercicio de sus funciones, la destitución, la multa, o incluso la prisión. Mientras que, por la segunda, si los Representantes no actúan según el interés del pueblo las consecuencias que se generarían son la pérdida de la confianza o el rechazo, que puede llevar a la realización de protestas sociales, o al momento de las elecciones, a la terminación de la representación en el cargo que se ocupa por la no reelección ${ }^{19}$.

Teniendo en cuenta lo anterior, con la finalidad de identificar si los Representantes son responsables frente a sus electores en Colombia, se hace necesario analizar en primer lugar, la aparición del Régimen Representativo (A); para luego analizar, en segundo lugar, las obligaciones de los Representantes en este régimen (B).

\section{I.A. La aparición del Régimen Representativo}

En la democracia directa puesta en práctica en Atenas entre los siglos VI y IV antes de Cristo, los ciudadanos «se reunían en el Ágora, en un número aproximado a los cinco mil, para discutir los asuntos fundamentales de la polis» ${ }^{20}$. Sin embargo, la Asamblea Popular no tenía todos los poderes, puesto que muchas funciones importantes eran ejercidas por Consejos o por funcionarios elegidos o nombrados por sorteo. Además, «algunas funciones importantes eran ocupadas por magistrados elegidos,

19 García, J. (1998), «Responsabilidad política y responsabilidad penal», Revista Española de Derecho Constitución, año 18, núm. 52, p. 85. «La responsabilidad política no se cierne sobre conductas ilícitas, sino lícitas; no descansa sobre criterios de legalidad, sino de oportunidad y, en suma, "no persigue castigar al culpable o asegurar la reparación de un daño, sino ratificar la idea de que los gobernantes están al servicio de los gobernados”». Ibídem, p. 85. Ver: Avril, P. (1977), «Pouvoir et responsabilité», en Le pouvoir: Mélanges offerts à Georges Burdeau, París, LGDJ, p. 9

20 Escobar, I. (2002), «El sistema representativo y la democracia directa», en Concha, H. (dir.), Sistema representativo y democracia semidirecta, México, UNAM, p. 127

N. ${ }^{\circ} 111$, mayo-agosto 2021, págs. 315-342 
aunque [...] la mayoría de las tareas que la Asamblea no realizaba, eran confiadas a ciudadanos designados por sorteo» ${ }^{21}$.

En la antigua Atenas eran «designados por elección los magistrados que tenían competencias consideradas absolutamente vitales: [tales como], los generales (stratègoi) y los altos funcionarios militares desde el siglo $\mathrm{V}$, y también los principales magistrados financieros creados y reformados en el siglo IV ${ }^{22}$. Sin embargo, la mayor parte de los funcionarios públicos existentes en la antigua Atenas fueron funcionarios designados por sorteo. Entre «los 700 magistrados que tenía la administración ateniense, cerca de 600 era designados por sorteo. Las magistraturas asignadas por sorteo (Klèros) eran generalmente colegiales y duraban un año. Un ciudadano no podía ejercer mas de una vez la misma magistratura y, aunque podía ser nombrado a varias magistraturas diferentes en el transcurso de su vida, el calendario de la rendición de cuentas (que impedía el acceso a una nueva función sin haber rendido cuentas por la precedente) imposibilitaba de hecho, que un individuo fuera magistrado dos años seguidos» ${ }^{23}$.

En la actualidad puede parecer inadmisible la designación por sorteo, puesto que podría llevar a la escogencia de personas sin las competencias necesarias para gobernar. No obstante, la selección por sorteo no ponía en riesgo la calidad del gobierno, porque los atenienses adoptaron importantes mecanismos jurídicos de control para hacer responsables y poder excluir a los funcionarios que no estuvieran a la altura de las expectativas. Así, todos los funcionarios públicos, escogidos por elección o por sorteo «estaban sujetos a la vigilancia constante de la Asamblea y los tribunales. No solo tenían que rendir cuentas (eû̂bynai) al momento de salir de sus cargos, sino que además durante su período, cualquier ciudadano podía en cualquier momento, presentar una acusación contra ellos y solicitar su suspensión» ${ }^{24}$.

Como estas disposiciones eran conocidas por todos, los atenienses sabían de antemano que si se postulaban para magistrados y eran seleccionados, serían responsables ante los demás ciudadanos y estarían sujetos a sanciones si se probaba sus faltas. Por esta razón, «no se hacía el sorteo entre todos los ciudadanos mayores de treinta años, sino solo entre los que se habían presentado ellos mismos, como candidatos» ${ }^{25}$.

De esta manera, se observa que en la democracia ateniense los magistrados elegidos por sorteo eran responsables jurídicamente frente a todos los demás ciudadanos, por los actos que realizaba en el ejercicio de sus funciones. Toda vez que cualquier ciudadano podía presentar en su contra y en cualquier momento una queja y si era

21 Manin, B. (1995), Principes du gouvernement représentatif, Paris, Flammarion, p. 19

22 Ibidem, p. 27

23 Ibidem, p. 24

24 Ibídem, p. 25. «En las Asambleas Principales (Ekklèsiai kyriai), la votación de los magistrados era incluso un tema obligatorio en la agenda. Cualquier ciudadano podía proponer un voto de censura contra un magistrado (ya sea que hubiera sido elegido por sorteo o por elección) y si se aprobaba la censura, el magistrado era suspendido de inmediato y su caso se remitía a los tribunales quienes podían absolverlo (en cuyo caso recuperaba sus deberes) o condenarlo». Ibidem, p. 25

25 Ibidem, p. 25 
aceptada por la Asamblea el magistrado era suspendido de sus funciones y juzgado por los tribunales judiciales. Es decir, existían lo que hoy en día se conoce como la Revocatoria de mandato por el incumplimiento de sus obligaciones ${ }^{26}$.

No obstante, la mayoría de los pensadores europeos y americanos del siglo XVIII y XIX consideraron que la democracia directa del tipo ateniense no era la forma de gobierno que debía adoptarse en los Estados modernos. Así, por ejemplo Montesquieu, en su famoso capítulo sobre la Constitución de Inglaterra, afirmó que «en los Estados libres, donde todo hombre, en quien se reconoce un alma libre, debe gobernarse a sí [mismo], sería preciso que el poder legislativo correspondiese al pueblo en cuerpo; pero como esto no es posible en los Estados de mucha extensión y ofrece numerosos inconvenientes en los pequeños, se necesita que el pueblo haga por medio de sus Representantes lo que no puede hacer por sí mismo ${ }^{27}$. De esta manera, consideraba que la mejor forma de gobierno a adoptar era el Régimen Representativo, o la República, como también se le conocía en aquella época, porque tenía la ventaja de permitir la elección de buenos Representantes, «capaces de discutir asuntos, [puesto que] el pueblo no es del todo idóneo para esto, lo que constituye uno de los mayores inconvenientes de la democracia» ${ }^{28}$.

Sin embargo, importantes voces se elevaron en contra de una de las características principales del Régimen Representativo, en el cual la participación del pueblo en el ejercicio del poder político se limitaba a la elección de los Representantes. Así, partiendo del hecho que el pueblo soberano no puede delegar en sus Representantes el ejercicio de la soberanía, Rousseau afirmó que «no siendo la soberanía sino el ejercicio de la voluntad general, no puede enajenarse jamás, y el soberano, que no es sino un ser colectivo, no puede ser representado más que por sí mismo» ${ }^{29}$. De esta manera, los diputados encargados de ejecutar las decisiones tomadas por el pueblo «no son, pues, ni pueden ser, sus Representantes; no son sino sus comisarios; [porque] no pueden acordar nada definitivamente. Toda ley no ratificada en persona por el pueblo es nula; no es una ley» ${ }^{30}$.

No obstante, no fueron las ideas de Rousseau las que triunfaron en los Estados Unidos de América cuando fue redactada la Constitución en la Convención de Filadelfia. Es así, como uno de sus principales redactores, James Madison, consideraba que el Régimen Representativo era preferible respecto a la democracia ${ }^{31}$, porque hacía pasar la opinión pública a través de un filtro que realizaban los mejores ciudadanos elegidos

26 Eberhardt, M. (2018), «La revocatoria de mandato en Colombia: diseño institucional y resultados de su aplicación», Revista de Derecho Político, núm. 103, p. 455

27 Montesquieu, Ch. (1906), El espíritu de las leyes, Tomo I, Madrid, Librería general de Victoriano Suarez, p. 230

28 Ibídem, p. 231

29 Rousseau, J.-J. (2007), El contrato social, Madrid, Editorial Esposa Calpe S.A., p. 55

30 Ibídem, p. 122

31 «La forma de gobierno que Madison llama democracia, siguiendo la lección de los clásicos que llega hasta Rousseau, era la democracia directa; en cambio por república, entiende el gobierno representativo, precisamente la forma de gobierno que hoy nosotros, $[\ldots .$.$] llamamos sin necesidad de especifica-$

N. ${ }^{\circ} 111$, mayo-agosto 2021, págs. 315-342 
popularmente, para que ellos, con una gran prudencia, identificaran el verdadero interés del país sobre todas las consideraciones impulsivas y egoístas de los demás ciudadanos. Es por ello que, el mismo James Madison afirmaba que «con este sistema, es muy posible que la voz pública, expresada por los Representantes del pueblo, esté más en consonancia con el bien público que si la expresara el pueblo mismo convocado con ese fin $»^{32}$.

Según Madison, para elegir adecuadamente a los Representantes y garantizar la correcta representación, se debe identificar el buen número de electores que debe encargarse de elegirlos. Toda vez que, «ampliando mucho el número de los electores, se corre el riesgo de que el Representante esté poco familiarizado con las circunstancias locales y con los intereses menos importantes de aquéllos; y reduciéndolo demasiado, se ata al Representante excesivamente a estos intereses, y se le incapacita para comprender los grandes fines nacionales y dedicarse a ellos» ${ }^{33}$.

De manera similar a la concepción existente en los Estados Unidos, en la Asamblea nacional convocada en la Revolución francesa, se distinguía también entre la democracia directa y el Régimen Representativo y se prefería esta última forma de gobierno. Es así, como uno de los principales miembros de esta Asamblea, Emanuel Sieyès, consideraba que el Régimen Representativo era mejor que la democracia ${ }^{34}$, pero no porque llevara a la producción de decisiones menos parciales y apasionadas, sino «porque era la forma de gobierno más apropiada para las condiciones de las «sociedades comerciales modernas», donde los individuos se dedican principalmente a producir y distribuir la riqueza» ${ }^{35}$.

De esta manera, se observa que «para Sieyès, como para Madison, el gobierno representativo no era una modalidad de la democracia, sino una forma de gobierno esencialmente diferente y, además, preferible» ${ }^{36}$. Es esta la razón por la cual en los Estados Unidos de Norteamérica y en Francia se adoptó este régimen para organizar sus gobiernos luego de la Independencia y de la Revolución. Sin embargo, la afirmación de un Régimen Representativo genera unas relaciones particulares entre los Representantes y los electores diferentes a las existentes en una democracia. De esta forma, es necesario analizar cuales son las obligaciones que tienen los Representantes en los Regímenes Representativos con la finalidad de comprender la responsabilidad que estos tienen frente a sus electores.

ciones ulteriores democracia que contraponemos a todas las formas antiguas y nuevas de autocracia». Bobbio, N. (2018), Estado, gobierno y sociedad, México, Fondo de cultura económica, p. 211

32 Madison, J. (2014), «El Federalista $\mathrm{N}^{\circ} 10$ », en Hamilton, A., Madison, J. y Jay, J., El federalista, México, Fondo de cultura económica, p. 40

33 Ibídem, p. 40

34 Sieyès, E. (1789), Quelques idées de constitution applicables à la ville de Paris, Versailles, Baudouin, Imprimeur de l'Assemblée nationale, pp. 3-4

35 Manin, B. (1995), Principes du gouvernement représentatif... cit, p. 13

36 Ibídem, p. 14 


\section{I.B. Las obligaciones de los Representantes en el Régimen Representativo}

El Régimen Representativo es concebido como una forma de gobierno en el cual el pueblo, en lugar de tomar las decisiones directamente en Asamblea, elige periódicamente a unos Representantes para que ellos decidan por él ${ }^{37}$. Sin embargo, podría afirmarse que no hay mucha diferencia entre el Régimen Representativo y la democracia, porque en el primero de estos regímenes los Representantes deben decidir tal como se los ordenó el pueblo al momento de la elección. Así, sería el pueblo el que seguiría tomando las decisiones mas importantes, pero de manera indirecta.

No obstante, este análisis no es válido, porque en los Regímenes Representativos «el pueblo no toma indirectamente las decisiones políticas al elegir a individuos que luego se reúnen para cumplir su voluntad. El pueblo elige solamente entre varios candidatos a aquellos cuya voluntad se convertirá en decisiones públicas. [...] De esta manera, los Representantes no son los agentes encargados de implementar una voluntad popular expresada durante las elecciones» ${ }^{38}$.

Esta afirmación sorprende, porque va en contra de la concepción general de la representación que se produce en el derecho civil a través del contrato de mandato, que impone al Representante la obligación de cumplir estrictamente con las órdenes dadas por el representado. Así, el mandato que da el representado al Representante es imperativo, puesto que si no se respecta se genera un incumplimiento contractual que podría acarrearle al Representante las sanciones pactadas.

Esta concepción de la representación entre particulares, propia del derecho civil, fue empleada para la toma de decisiones públicas en la época feudal. Esto se debió a que los señores feudales tenían el derecho a ser convocados y la obligación a asistir a las convocatorias que el Rey hacía para pedirles ayuda y consejo, pero a partir del siglo XV se empezó a elegir a los Representantes de los señores que asistirían a las convocatorias del Rey. Estos Representantes no tenían poderes propios «sino sólo aquellos poderes que le confia[ban] sus comitentes» ${ }^{39}$. De esta manera, llegaban «a la asamblea, porta[ndo] las instrucciones y cuadernos que le remit[ían] sus electores; [tenían] obligación de conformarse a ellos y no [podían] conceder a la realeza sino lo que [les habían] autorizado sus mandantes» ${ }^{40}$. El Representante era responsable respecto a sus representados «del cumplimiento de su misión, y [estaba] obligado a rendirles cuenta

37 Así, Schumpeter definió el régimen representativo, llamándolo democracia, como «el sistema en el cual los individuos adquieren el poder de participar en la toma de decisiones políticas cuando ganan en la lucha competitiva por los votos del pueblo». Schumpeter, J. (2002), Capitalisme, socialisme et démocratie, Quebec, Université de Quebec, p. 318.

38 Manin, B. (1995), Principes du gouvernement représentatif... cit, p. 208

39 Carre de Malberg, R. (2001), Teoría general del Estado, México, UNAM, p. 1013

$40 \quad$ Ibídem, p. 1013

N. o 111, mayo-agosto 2021, págs. 315-342 
de sus actos; los electores [podían] también desaprobarlo y hasta revocarlo. Finalmente, como todo mandatario, [tenían] derecho a ser indemnizado de sus gastos» ${ }^{41}$.

El mandato imperativo permitía garantizar que las decisiones de los Representantes fueran conformes a la voluntad de los electores, puesto que los primeros solo podían decidir según las instrucciones que habían recibido de los segundos. Así, eran los electores quienes tomaban las decisiones mas importantes, pero de forma indirecta. Sin embargo, el mandato imperativo no permitía garantizar la participación indirecta de los electores en la toma de las decisiones mas importantes, cuando el Representante tuviera que decidir sobre cuestiones desconocidas al momento de su elección, puesto que en este caso sería imposible que hubiera recibido instrucciones sobre ello.

Para estar seguros de que las decisiones aprobadas por los Representantes fueran conformes a la voluntad real de sus electores, los primeros debían rendir cuenta de sus actos a los segundos y podían ser revocados en cualquier momento. Esto, por cuanto «la revocabilidad brinda a los Representantes la oportunidad de lidiar con situaciones no previstas en el momento de la elección, pero al mismo tiempo, garantiza la coincidencia entre la voluntad de los electores y la decisión de los gobernantes, ya que los electores pueden sancionar inmediatamente a los Representantes cuyas decisiones desaprueban» ${ }^{42}$.

Teniendo en cuenta la concepción de la representación existente en la Edad media, propia del derecho civil, se ha creído que los Representantes en los Regímenes Representativos actuales están obligados a representar la voluntad del pueblo «en virtud de una delegación o comisión que les ha sido dada por los electores-mandantes» ${ }^{43}$. Sin embargo, no hay que olvidar que el Régimen Representativo pretende la elección de «hombres esclarecidos, tomados entre lo mejor de los ciudadanos y que posean actitudes suficientes para dirigir los asuntos del Estado» ${ }^{44}$. Es por ello que «los Representantes, lejos de tener que obedecer las órdenes populares, son llamados, por el contrario, a gobernar al pueblo, tomando a este efecto las medidas que le parecen mas convenientes ${ }^{45}$.

41 Ibídem, p. 1013. En la época feudal, la representación tenía «restringidos contornos, pues el Representante únicamente podía operar dentro de los límites que el mandato le confería, y que venían puntualmente establecidos en los cuadernos de instrucciones (cabiers d'instructions). Hasta el punto de que el Representante se obligaba personalmente con sus propios bienes a reparar los perjuicios causados si sobrepasaba los límites del mandato, además de producirse, en ese caso, la revocación del mismo». De Vega, Pedro (1985), «Significado constitucional de la representación política», Revista de Estudios Políticos, núm. 44, p. 26. Ver también: Dahl, R. (2002), La Democracia y sus críticos..., cit, pp. 41 y s.

42 Manin, B. (1995), Principes du gouvernement représentatif... cit, p. 213

43 Carre de Malberg, R. (2001), Teoría general del Estado..., cit, p. 923. Así, por ejemplo, para Mainwaring, Bejarano y Pizarro el elemento central de la representación es «la autorización otorgada por un principal a un agente para actuar en su nombre». Mainwaring, S., Bejarano, A., y Pizarro, E. (eds.) (2008). La crisis de la representación democrática..., cit. p. 39.

44 Carre de Malberg, R. (2001), Teoría general del Estado..., cit, p. 921

45 Ibidem, p. 922 
De esta manera, por las razones mismas que llevaron a su adopción, en los Regímenes Representativos, un Representante no recibe de sus electores un «mandato que lo encadene, sino que ejerce una función libre. No expresa la voluntad de sus electores, sino que decide por si mismo y bajo su propia apreciación. No habla ni vota en nombre y de parte de sus electores, sino que forma su opinión y emite su sufragio según su conciencia y sus opiniones. En una palabra, es independiente con respecto a sus electores» ${ }^{46}$. Es así, como la elección es «un procedimiento aristocrático u oligárquico, ya que reserva los cargos públicos a individuos eminentes a quienes sus conciudadanos consideran superiores a los demás» ${ }^{47}$.

Esta situación se presenta actualmente, porque «los Regímenes Representativos no admiten, o incluso prohíben explícitamente, dos instituciones que privan a los Representantes de cualquier dependencia: el mandato imperativo y la revocatoria permanente de los Representantes electos» ${ }^{48}$. Es así, como por ejemplo en los Estados Unidos de América, cuando el primer Congreso elegido discutió las diez primeras enmiendas a la Constitución, se propuso incluir en la primera enmienda, que garantiza la libertad de consciencia y de expresión, el derecho de los electores a dar instrucciones a sus Representantes. Sin embargo, la propuesta fue finalmente rechazada. De esta manera, «los votantes estadounidenses tenían todavía la libertad de dar instrucciones a sus Representantes si lo querían, pero estas no tenían fuerza vinculante y su incumplimiento no podía ser sancionado» ${ }^{49}$.

De igual forma, en Francia, se les entregaron a los diputados elegidos para los Estados Generales instrucciones específicas para que ellos las discutieran en la Asamblea que se formó al momento de la Revolución. Sin embargo, «una de las primeras decisiones de la Asamblea Nacional fue prohibir, a partir de julio de 1789, la práctica del mandato imperativo" ${ }^{50}$.

De otra parte, la revocabilidad permanente no se ha establecido de manera sostenible en ninguno de los Estados modernos que adoptaron el Régimen Representativo. Así, por ejemplo, en Francia la Constitución votada por la Asamblea en 1793 dispuso que los funcionarios electos fueran revocables en cualquier momento de su mandato por parte de las Asambleas electorales locales. Sin embargo, la Constitución no llegó a entrar en vigor. De igual forma, casi un siglo después, en la Comuna de París de 1871, se estableció un sistema de revocabilidad permanente de los miembros del Consejo. No obstante, la práctica «tuvo tan corta vida como la propia Comuna» ${ }^{51}$.

46 Ibídem, p. 929. De esta forma, «la figura del mandato político no puede ser explicada sobre los mismos fundamentos que el de índole civil». Ramírez, G. (2000), «Mandato imperativo y mandato representativo. Una perspectiva diversa el caso colombiano», Revista Derecho del Estado, núm. 8, p. 159.

47 Manin, B. (1995), Principes du gouvernement représentatif... cit, p. 307

48 Ibidem, p. 209

49 Ibidem, p. 211

50 Ibídem, p. 211

51 Ibídem, p. 211

(C) UNED. Revista de Derecho Politico

N. ${ }^{\circ} 111$, mayo-agosto 2021, págs. 315-342 
De esta manera, en los Regímenes Representativos «el diputado no es ni mandatario, ni delegado, ni Representante de sus electores. Es su elegido, pero no su comisario» ${ }^{52}$. Por tanto, «no puede decirse que haya representación de una voluntad por otra; lo cierto es que ya no subsiste, en semejante estado de cosas, sino una voluntad única: la de la persona que tiene el poder de decidir libremente por cuenta ajena» ${ }^{53}$.

El Régimen Representativo no es entonces un Régimen de representación en el verdadero sentido de la palabra, puesto que los Representantes no representan la voluntad real de sus electores. Así, «lo que el pueblo da a sus elegidos en la elección no es un mandato, sino su confianza» ${ }^{54}$. Pero esta confianza puede ser desconocida por el Representante, quien no tiene la obligación jurídica de acatar la voluntad de sus electores. De esta forma, una de las diferencias mas importantes entre el Régimen Representativo y el gobierno del pueblo no obedece a la existencia de Representantes, sino a la independencia de estos últimos de la voluntad real de sus electores ${ }^{55}$.

Sin embargo, persiste una duda: si los Representantes no están obligados a votar los proyectos de ley de cierta forma, ni tienen un mandato imperativo ¿de que sirven las promesas que hacen en sus campañas? En realidad, los Representantes son libres de cumplir con las promesas que les hicieron a sus electores en sus compañas, puesto que de su incumplimiento no se deriva ninguna sanción jurídica. Solo se genera una responsabilidad política, toda vez que «el que ha hecho compromisos con sus electores puede pensar que, si no los ejecuta, no será reelegido. Pero, por un lado, tiene la libertad de sacrificar la perspectiva de su reelección si, en circunstancias excepcionales, otras consideraciones le parecen más importantes que su propia carrera. Por otro lado, sobre todo, cuando llegue el momento de su reelección, puede tratar de convencer a sus electores de que finalmente tuvo razón al comportarse como lo hizo $y$, por lo tanto, traicionar sus promesas» ${ }^{56}$.

No obstante, esto no quiere decir, que no haya absolutamente ninguna relación entre la manera como los Representantes votan los proyectos de ley y la voluntad real de sus electores, puesto que los Representantes «por razón misma de su origen o de sus vínculos con el cuerpo nacional, se halla más o menos sometido a la influencia de las ideas y de los sentimientos que reinan en la nación; por consiguiente, las decisiones que tomen se inspirarán en el espíritu nacional» ${ }^{57}$. Aunque, esta influencia no es necesariamente muy fuerte en el caso que exista una distancia muy grande entre las condiciones sociales, económicas y territoriales de los electores y de los elegidos, porque en este caso los segundos no tendrán conocimiento de cuales son las ideas o los sentimientos de sus electores.

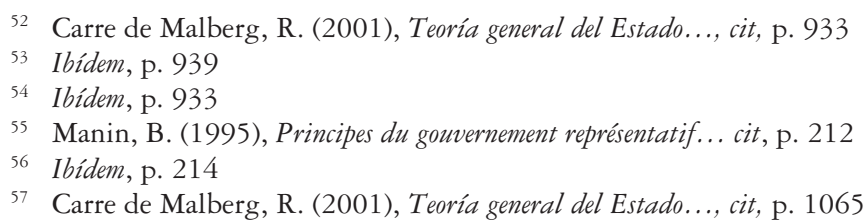


Todo esto lleva a concluir que en el Régimen Representativo, los Representantes no tienen desde un punto de vista jurídico, ninguna responsabilidad respecto a sus electores, puesto que, por un lado, no tienen la obligación jurídica de votar los proyectos de ley tal como lo desean sus electores, ni como lo prometieron en sus campañas electorales, toda vez que no existe el mandato imperativo. Por otro lado, ninguna consecuencia jurídica se genera en contra del Representante o de la ley que se adoptó, gracias a un voto que traicionó la voluntad de sus electores, puesto que este comportamiento no genera un vicio en la formación de la ley y no existe tampoco la revocabilidad permanente en contra de los Representantes por el incumplimiento de sus promesas.

Sin embargo, el hecho que los Representantes no tengan la responsabilidad jurídica de decidir o actuar según la voluntad de sus electores, no quiere decir, que no estén obligados políticamente a hacerlo, puesto que si no lo hacen el pueblo puede, como sucedió en varios Estados latinoamericanos en el segundo semestre del año 2019, salir a las calles y exigir a través de manifestaciones públicas, que su voluntad sea escuchada y sea tenida en cuenta por los Representantes al momento de decidir ${ }^{58}$.

De esta forma, con la finalidad de definir la responsabilidad de los Representantes frente a sus electores en Colombia, se hace necesario analizar cual es la forma de gobierno adoptada en este país y cuales son las obligaciones que le impone a los Representantes.

\section{LAS OBLIGACIONES DE LOS REPRESENTANTES EN COLOMBIA}

Los Estados latinoamericanos actuales, y entre ellos Colombia, tienen sus orígenes en el Régimen Representativo que gradualmente se estableció en los Estados Unidos y en Francia. Este régimen, no obstante sus múltiples limitaciones, ha permitido a estos Estados construir gobiernos protectores de los derechos humanos y capaces de satisfacer las necesidades básicas de sus ciudadanos.

Es por esta razón que se hace necesario, por una parte, indagar cual es la forma de gobierno que se adoptó en Colombia desde sus inicios, con la finalidad de identificar cuales son las obligaciones que tienen actualmente los Representantes frente a sus electores. Por otra parte, se hace necesario identificar las condiciones que permiten a los electores influenciar las decisiones que toman sus Representantes, con la finalidad de constatar si en la práctica los electores colombianos son capaces de

58 Así, en el mes de julio del año 2019 las protestas sociales llevaron al Gobernador de Puerto Rico a renunciar a su cargo. Ver: BBC (2019), «Crisis en Puerto Rico: Ricardo Rosselló renuncia forzado por las intensas protestas tras el escándalo del chat», en https://www.bbc.com/mundo/noticias-america-latina-49074542. Mientras que en el mes de noviembre del mismo año las protestas forzaron la convocatoria a una Asamblea constituyente en Chile. Ver: BBC (2019), «Protestas en Chile: el gobierno anuncia que convocará un nuevo Congreso Constituyente», en https://www.bbc.com/mundo/noticias-america-latina-50370470

(C) UNED. Revista de Derecho Politico

N. ${ }^{\circ} 111$, mayo-agosto 2021, págs. 315-342 
influenciar las decisiones de sus Representantes. Para ello se analizará, en un primer lugar, el Régimen Representativo en Colombia (A); para luego analizar el reducido control sobre los Representantes en Colombia (B).

\section{II.A. El Régimen Representativo en Colombia}

El Régimen Representativo fue adoptado en Colombia desde el mismo momento en que empezó a afirmar su independencia ${ }^{59}$. De esta forma, justo después del grito de independencia, la Constitución de Cundinamarca de 1811 estableció una monarquía constitucional moderada por una Representación nacional (Artículo 1, Título III). Así, cuando el Rey de España fuese liberado podía asumir el trono, pero en su ausencia las funciones ejecutiva, legislativa y judicial eran ejercidas por Representantes elegidos por un colegio electoral. La Constitución adoptó además varias medidas especiales y generales para hacer a los Representantes jurídicamente responsables por sus decisiones y por sus actos.

Entre las medidas especiales, por ejemplo, se les impuso a los consejeros del presidente la obligación de dar inmediatamente parte al Senado cuando considerarán que el presidente había adoptado alguna providencia directa o indirectamente contraria a la Constitución (Artículo 6, Título V). También se previó como medida general para hacer responsable a los Representantes la creación de un órgano judicial, el Senado de censura, encargado de tramitar el juicio de residencia. Esta era una institución curiosa, puesto que según su reglamentación nadie era «llamado a cuentas antes de concluir su servicio, pero al concluirlo, ni los legisladores escapa[ba]n del juicio de residencia» ${ }^{60}$.

A través de estas medidas se configuró en la Constitución de Cundinamarca de 1811 una responsabilidad jurídica para los Representantes, puesto que tenían que rendir cuentas al momento de salir de sus cargos. De esta forma, de manera similar a como pasaba en la antigua Atenas, había un mecanismo de revocatoria de mandato que permitía sancionar a los Representante si se comprobaba que había cometido una falta ${ }^{61}$.

Sin embargo, las cosas cambiaron luego de la Guerra de Independencia, cuando se adoptó el Régimen Representativo en su forma moderna. Esto se observa, en primer lugar, en el Reglamento electoral para el Segundo Congreso de Venezuela, ratificado

59 Esta escogencia, tiene como inspiración mas próxima las ideas sobre la representación adoptadas en la España continental luego de los acontecimientos producidos a partir de 1808, cuando Napoleón Bonaparte tomó el control de la península. Ver: Guerra, F. (1992), Modernidad e independencias, Madrid, Mafre.

60 Samper, J. (1951), Derecho público interno de Colombia, Bogotá, Biblioteca popular de cultura colombiana, p. 86

${ }^{61}$ «Bajo esta disposición se residenció a Jorge Tadeo Lozano, José María Domínguez y Manuel Camacho y Quesada, expresidente y exsenadores, respectivamente». Malagón, M. (2012), Los modelos de control administrativo en Colombia (1811-2011), Bogotá, Ediciones Uniandes, p. 83. Sin embargo, la institución dependía de lo que el Senado de censura entendiera por actuar en contra de la Constitución y según las ideas de la época, no se desconocía la Constitución cuando se votaba un proyecto de ley de manera diferente a lo prometido a sus electores. 
por el Consejo de Estado presidido por Simón Bolívar el 24 de noviembre de 1818, a través del cual se elegirían a los Representantes para el Congreso de Angostura. Puesto que en él se afirma que «ninguno de los que resulten nombrados ha de ceñir sus ideas ni su representación al distrito de su nombramiento, ni a cualquiera otro en particular, sino generalmente a todas y cada una de las porciones de Venezuela» ${ }^{62}$. De esta manera, en los inicios de la actual Colombia, tal como sucedió en Francia y en los Estados Unidos, se excluyó la posibilidad de otorgar a los Representantes un mandato imperativo, puesto que ellos no podían votar según la voluntad de sus electores sino teniendo en cuenta los intereses de todos los ciudadanos ${ }^{63}$.

En segundo lugar, los Representantes no eran elegidos para comunicar una voluntad que no les era propia, sino que eran elegidos para expresar su propia voluntad por el bien de toda la provincia, toda vez que los elegidos debían ser los mejores de entre todos los ciudadanos. Esto se observa claramente en la proclama de Simón Bolívar a los venezolanos del 22 de octubre de 1818, cuando se afirma que «elegid por magistrados a los más virtuosos de vuestros conciudadanos y olvidad, si podéis, en vuestras elecciones, a los que os han libertado» ${ }^{64}$. Aquí se observa claramente el elemento aristocrático del Régimen Representativo adoptado al momento en que se establece el Estado colombiano, puesto que este «fue instituido con la plena conciencia de que los Representantes electos serían ciudadanos distinguidos» ${ }^{65}$.

La exclusión del mandato imperativo y la aceptación del componente aristocrático, propios del Régimen Representativo, fueron luego acompañados en la Constitución de 1821 con la eliminación de los mecanismos jurídicos de revocatoria de mandato, cuando se afirmó expresamente en el artículo 66, respecto a los miembros del Congreso, que no eran «responsables por los discursos y opiniones que hayan manifestado en las Cámaras ante ninguna autoridad y en ningún tiempo». A través de estas nuevas disposiciones los Representantes en las Cámaras legislativas dejaron de ser jurídicamente responsables frente a sus electores.

La manera como se configuró la responsabilidad de los Representantes en la Constitución de 1821 fue luego reiterada de una manera muy similar en las Constituciones de 1830, 1843, 1853, 1858 y 1863. Aunque, en las Constituciones de 1843 a 1863 se pasó a afirmar expresamente que «los Senadores y Representantes no son responsables, en ningún tiempo, ni ante autoridad alguna, por las opiniones que manifiesten y votos que den en las Cámaras o en el Congreso» (Artículo 63, Consti-

62 Rivas, G. (ed.) (1998), Correo de Orinoco, Angostura (Venezuela) 1818-1821, Bogotá, FICA, p. 55

63 Aunque en esta época los electores era un grupo reducido de ciudadanos. Ver: Ospina, M. y Marín, J. (2018), «Ciudadanía y elecciones en la Nueva Granada. Las definiciones y su reglamentación en 1821-1853», Revista de historia regional y local, vol. 10, núm. 20, pp. 102-132.

64 Rivas, G. (ed.) (1998), Correo de Orinoco..., cit, p. 53

65 Almarza, Á. (2017), Los inicios del gobierno representativo en la República de Colombia 1818-1821, Madrid, Marcial Pons, p. 59. «Esta idea de distinción se fundamentó en dos principios básicos: el primero, en la importancia de garantizar que los Representantes mantuvieran una independencia económica; y el segundo, que su prestigio permitiera la búsqueda del bien general de la sociedad, y no de intereses particulares». Ibídem, p. 59

N. ${ }^{\circ} 111$, mayo-agosto 2021, págs. 315-342 
tución de 1843$)^{66}$. Esta afirmación se hizo, aunque estas Constituciones declaraban expresamente establecer un Régimen Representativo y responsable.

A través de esta disposición los Representantes en las Cámaras legislativas pasaron a ser absolutamente irresponsables frente a sus electores, no solo por sus opiniones, sino también por los votos que emitían. De esta forma, los miembros de las Cámaras podían desconocer libremente las promesas hechas a sus electores en sus campañas electorales, e incluso votar en contra de sus promesas, puesto que ninguna responsabilidad podía generarse por sus votos en las Cámaras. «Si la eliminación del mandato imperativo significó un progreso en aras de la independencia de los Representantes, para los ciudadanos se convirtió en la eliminación del único vínculo posible de control a sus elegidos» ${ }^{67}$.

En la Constitución de 1886, se reiteró en el artículo 106 que «los Senadores y los Representantes son inviolables por su opiniones y votos en el ejercicio de su cargo». Además, se afirmó en el artículo 105 que «los individuos de una y otra Cámara representan a la Nación entera, y deberán votar consultando únicamente la justicia y el bien común». Así, lejos de tener que representar la voluntad real de sus electores, los Representantes tenían simplemente el deber de votar los proyectos de ley consultando su propio concepto de lo que es justo y de lo que genera el bien común.

Sin embargo, no existía certeza alguna que permitiera asegurar que la idea de justicia y de bien común que podían tener los Representantes, coincidía con la idea que sus electores o la mayoría del pueblo podían tener. Es difícil creer que las ideas de los Representantes en el Congreso coincidían con las de la mayoría del pueblo colombiano, porque tradicionalmente los candidatos que en últimas han sido elegidos para las Cámaras legislativa en Colombia han sido en su mayoría, personas que proceden de niveles sociales altos, de las ciudades capitales y con niveles de educación muy diferentes a las de la mayoría de los colombianos. De esta forma, no siendo conscientes de las realidades sociales que han vivido la mayor parte del pueblo colombiano, difícilmente podían tener el mismo concepto de justicia y de bien común que tenía el pueblo.

En la Constitución de 1991 se reiteró en el inciso primero del artículo 133 y en el artículo 185 la dos mismas disposiciones mencionadas de la Constitución de 1886. Aunque, también se afirmó, en el inciso segundo del artículo 133 que los elegidos son responsables «políticamente ante la sociedad y frente a sus electores del cumplimiento de las obligaciones propias de su investidura».

Sin embargo, para la Corte constitucional colombiana el hecho que los elegidos sean responsables políticamente no implica que estos deban votar los proyectos de ley según la voluntad real de sus electores o en el sentido que prometieron en sus campañas electorales o según los principios de sus partidos políticos, puesto que siguen siendo irresponsables por sus votos.

66 Ver también: Constitución de 1853 (Artículo 18), Constitución de 1858 (Artículo 26), Constitución de 1863 (Artículo 22)

${ }_{67}$ Rodríguez, M. (2004), «La acción pública de inconstitucionalidad como mecanismo corrector de la crisis de representación en Colombia, 1910- 2003», Análisis político, núm. 52, p. 24 
De esta forma, la Corte constitucional comenzó afirmando en la sentencia C-011 del 21 de enero de 1994, que en la Constitución de 1991 se mantuvo «la democracia representativa y se adicionó la participativa». Luego, en la sentencia C-179 del 12 de marzo de 2002, la Corte constitucional explicó que "en la democracia representativa, los funcionarios públicos elegidos democráticamente representan a la nación entera y no a sus electores individualmente considerados, por lo cual el mandato que reciben no les impone obligaciones frente a los electores. Tal mandato se denomina "representativo». [Mientras que] en la democracia participativa, los elegidos representan la voluntad del pueblo y reciben un mandato imperativo.

No obstante, la Corte constitucional en su sentencia C-342 del 3 de mayo de 2006 observó que «para las Corporaciones de elección popular no puede hablarse de mandato imperativo, pues no está en los Representantes de un partido concretar todo el programa, la razón de ser, la naturaleza de los órganos colegiados es la negociación, el consenso y la conclusión en la ley de las decisiones más próximas a un ideario. No puede exigírseles mandato imperativo, ni revocatoria del mandato ${ }^{68}$. Así las cosas, en el sistema actual, [...] no existen responsabilidades directas entre elector y Representante por incumplimientos del mandato. Aunque, tal y como lo afirmó Corte constitucional en su sentencia C-150 del 8 de abril de 2015, esta no es la situación de los alcaldes y gobernadores, para quienes existe exclusivamente la revocatoria de mandato, que le da la posibilidad al «pueblo de responsabilizar políticamente el incumplimiento de aquello que haya prometido determinado candidato y por lo cual fue elegido» ${ }^{69}$.

De esta manera, se constata que la forma de gobierno adoptada en el Estado colombiano desde sus inicios es el Régimen Representativo, aunque en la actualidad la Corte constitucional la llama democracia representativa. En esta forma de gobierno los Representantes de las Cámaras legislativas son irresponsables jurídicamente ante sus electores por la manera en que votan los proyectos de ley, puesto que ninguna sanción se genera en contra de sus personas o de las leyes que aprobaron, por el hecho de haber votado de modo diferente o incluso contrario a la manera como prometieron que lo haría en sus campañas electorales o como afirman públicamente los jefes de los partidos que van a votar. Esta concepción es compartida por la Corte Suprema de Justicia, quien también afirmó recientemente que el «incumplimiento de promesas o compromisos electorales no es delito, ni genera responsabilidad penal» ${ }^{70}$.

68 La concepción realizada por la Corte constitucional coincide con lo observado por Gonzalo Ramírez, cuando afirmó que «la Constitución Política de Colombia, aunque no rechaza de manera directa el mandato imperativo, entiende que el mandato del Representante debe ser representativo, ya que «representan al pueblo», sin embargo limita esta representación afirmando que deberá actuar "consultando la justicia y el bien común”». Ramírez, G. (2000), Mandato imperativo y mandato representativo... cit, p. 163.

69 Ver también: Eberhardt, M. (2018), La revocatoria de mandato en Colombia... cit

70 Vanguardia (2019), Incumplir promesas electorales no es delito: Corte Suprema, en: https:// www.vanguardia.com/colombia/incumplir-promesas-electorales-no-es-delito-corte-supremaCI1486411 [15 de junio de 2020].

(C) UNED. Revista de Derecho Politico

N. ${ }^{\circ} 111$, mayo-agosto 2021, págs. 315-342 
Esta situación en particular ha contribuido en gran parte a la aparición de manifestaciones sociales en el segundo semestre del año 2019 y de nuevo en el mes de abril de 2021 en Colombia, puesto que la inexistencia de una obligación jurídica de los Representantes de escuchar a sus electores y de votar los proyectos de ley según su voluntad real, ha generado un distanciamiento entre las políticas públicas y la voluntad del pueblo, que no se soporta mas. Con la finalidad de que los intereses de los electores sean realmente representados los ciudadanos han tenido que movilizarse socialmente para que los Representantes no los sigan ignorando. No obstante, varios medios de comunicación adviertieron en el 2019 que las movilizaciones no lograron su cometido en Colombia, porque se siguen adoptando leyes que van en contra de los propósitos que persiguen muchos de los marchantes ${ }^{71}$.

Es por eso que se hace necesario analizar, como en los otros países del mundo se ha cerrado la brecha entre electores y Representantes, para lograr una real representación de sus intereses y así poder constatar si esos mismos mecanismos podrían ser adoptados en Colombia.

\section{II.B. El reducido control sobre los Representantes en Colombia}

La manera como está regulada las obligaciones para los Representantes en los Regímenes Representativos no parece ser la mas indicada para garantizar que la voluntad real de los electores sea correctamente representada. Sin embargo, no hay que olvidar que las características de este régimen fueron escogidas entre varias opciones, «se optó por las elecciones en lugar de las loterías o la monarquía hereditaria. La libertad de opinión fue una alternativa a los mandatos imperativos y a la revocación. [...] Finalmente, las elecciones periódicas se escogieron sobre los términos vitalicios» ${ }^{72}$.

El Régimen Representativo adoptó estas características, a pesar de sus múltiples falencias, puesto que se creyó que son las que «mejor combinan la autoridad necesaria para que los Representantes estén en capacidad de gobernar, con las precauciones que podrían asegurar que gobernarán bien, en salvaguarda del interés de los representados. Estas instituciones garantizan a los Representantes la autorización para mandar, pero no confían en la virtud de los Representantes para asegurar que mandarán bien, por lo que introducen varias precauciones «verticales»y «horizontales» a tal efecto» ${ }^{73}$.

Entre las precauciones horizontales se encuentran la separación de poderes, el control jerárquico entre los funcionarios administrativos, las autoridades administrativas independientes y la descentralización ${ }^{74}$. Mientras que las precauciones verticales

71 Ver, por ejemplo: DW (2019), «Colombia aprueba polémica reforma fiscal que rebaja impuestos a las grandes empresas», en: https://www.dw.com/es/colombia-aprueba-polémica-reforma-fiscal-que-rebaja-impuestos-a-las-grandes-empresas/a-51756571

72 Przeworski, A. (1998), «Democracia y representación», Reforma y democracia, núm. 10, p. 8

73 Ibídem, p. 8

74 Ibidem, pp. 21-25 
configuran una responsabilidad política entre los Representantes y los electores, que se genera cuando se exige que los Representantes deban ser periódicamente electos o reelectos por los ciudadanos. De esta forma, «si las elecciones son libremente disputadas, si la participación es ilimitada, y si los ciudadanos gozan de libertades políticas, entonces los gobiernos actuarán de acuerdo con el mejor interés del pueblo» ${ }^{75}$. Nos centraremos en el análisis de los mecanismos de responsabilidad vertical, puesto que en ellos los electores juegan un papel mas importante.

Analizando los mecanismos de responsabilidad vertical, se observa que la relación que se configura entre los electores y sus Representantes puede ser entendida desde dos puntos de vista diferentes. Por un lado, desde el punto de vista del mandato, se afirma que «las elecciones sirven para elegir las buenas políticas y los políticos que apoyan tales políticas» ${ }^{76}$. Así, los Representantes elegidos tienen el mandato de implementar estas políticas, sobre todo si están interesados en su reelección. Por otro lado, desde el punto de vista de la representación, se considera que «los gobiernos son responsables si los votantes tienen oportunidad de discernir si están actuando en función de sus intereses y sancionarlos oportunamente, de modo que aquellos gobernantes electos que actúen de acuerdo con el interés de los ciudadanos puedan resultar reelectos y que quienes actúen en sentido contrario a dicho interés no lo sean» ${ }^{77}$.

Sin embargo, se critica fuertemente la capacidad que tienen las elecciones periódicas por si solas para garantizar que los Representantes van siempre a actuar buscando el bien de los electores, sea cual sea el punto de vista que se adopte. Toda vez que «las elecciones no obligan a los políticos a implementar las políticas preferidas por los votantes. A su vez, los ciudadanos no tienen suficiente información como para evaluar a los gobiernos electos, y la amenaza de no ser reelectos no es suficiente para inducir a los gobiernos a actuar en beneficio del interés del público» ${ }^{78}$. De esta forma, se ha observado que «la rendición de cuentas que se establece mediante las elecciones no es suficiente para garantizar un buen desempeño gubernamental y el Estado de Derecho» ${ }^{79}$. Esta ha sido una crítica recurrente a los Regímenes representativos, que se ha presentado sobre todo por los adeptos a la doctrina de la «democracia deliberativa», para quienes el problema de este Régimen se encuentra, en últimas, en que «más allá del «teatro democrático» que implican las elecciones periódicas, los ciudadanos comprend[ieron] que las decisiones políticas más importantes se toman a sus expensas, y que son los grupos de presión más poderosos los que acaban por imponer sus preferencias» ${ }^{80}$.

75 Ibídem, p. 9. Aunque, este listado puede ser mucho mas largo. Ver, por ejemplo: Dahl, R. (1989), La poliarquía. Participación y oposición, Madrid, Tecnos, p. 15

76 Przeworski, A. (1998), «Democracia y representación»..., cit, p. 9

77 Ibídem, p. 15. Este punto de vista «se basa en el voto retrospectivo». Ibídem, p. 15

78 Ibídem, p. 9

79 Ackerman, J. (2006), «Sociedad civil y rendición de cuentas»..., cit, p. 12

80 Martí, J. (2006), La república deliberativa. Una teoría de la democracia, Madrid, Marcial Pons, pp. 13-14. Como solución a esta dificultad los partidarios de esta doctrina proponen un modelo político nor-

(C) UNED. Revista de Derecho Politico

N. ${ }^{\circ} 111$, mayo-agosto 2021, págs. 315-342 
A pesar de todas las críticas mencionadas, es indudable que el Régimen Representativo ha permitido desarrollar Estados respetuosos de los derechos humanos, capaces de satisfacer por igual las necesidades básicas de todos sus ciudadanos, como sucede particularmente en el norte y el occidente de Europa o en Norteamérica.

No obstante, para que en el Régimen Representativo los electores puedan influenciar o sancionar a sus Representantes por las decisiones tomadas, se requiere necesariamente por lo menos, que los electores tengan la forma de conocer claramente la manera como sus Representantes están votando cada uno de los proyectos de ley y que puedan sancionarlos al momento de la reelección negándoles su voto.

Sin embargo, debido a la manera como esta reglamentado el Régimen Representativo en Colombia, se presentan grandes dificultades en estos dos aspectos ${ }^{81}$. Esto se debe, en primer lugar, a que si bien el Acto legislativo 01 de 2009, que adicionó el artículo 133 de la Constitución, afirma que «el voto de [los] miembros [de los cuerpos colegiados de elección directa debe ser] nominal y público, excepto en los casos que determine la ley», en realidad es muy difícil para lo votantes conocer en la práctica la manera como están votando sus Representantes. Esto se presenta por cuanto la manera como es publicado el sentido de los votos de los diferentes congresistas para cada proyecto de ley o de reforma constitucional debatido, no permite identificar fácilmente cual es el contenido del proyecto sometido a votación, ni cual es la ley definitiva en el caso que sea aprobada.

En las páginas de internet de la Cámara de Representantes y del Senado, como en la Gaceta del Congreso, se publican los resultados de las votaciones con el número que tiene el proyecto en la respectiva Cámara legislativa. De esta manera, para poder buscar el resultado de la votación de los proyectos de ley en la Gaceta o en internet y poder así conocer si un Representante aprobó o no la adopción de una ley en particular, los ciudadanos deben averiguar la fecha exacta de la votación del proyecto de ley en cada Cámara y el número con el cual se radicó en cada Cámara el proyecto de la ley, el cual no coincide necesariamente con el número definitivo de la ley. Así, por ejemplo, en la Gaceta del Congreso número 870, se muestra como cada miembro de la Cámara de Representantes votó el proyecto de ley $N^{\circ} 311$ de $2019^{82}$. Pero no existe una ley con

mativo que busca «que las decisiones políticas sean tomadas mediante un procedimiento de deliberación democrática». Ibídem, p. 23. Esto implica que en la toma de las decisiones públicas deben participar todos aquellos que resultarán afectados, o sus representantes y que las decisiones deben basarse en los argumentos racionales e imparciales propuestos por y a los participantes. Elster, J. (1998). Introduction, en Elster, J. (ed.). Deliberative Democracy, Cambridge, Cambridge University Press, p. 8 y s.

${ }_{81}$ Aunque, en Colombia existen también otros grandes problemas respecto a la manera como esta reglamentada las elecciones y a la organización electoral. Ver, por ejemplo: Mainwaring, S., Bejarano, A., y Pizarro, E. (eds.) (2008). La crisis de la representación democrática..., cit., García, M. y Revelo, J. (2010), Estado alterado, clientelismo, mafias y debilidad institucional en Colombia, Bogotá, Dejusticia, sobre todo páginas 162 a 203 y Duque, Javier (2012), «La subpoliarquía colombiana. Deficiencias estatales, democracia deficitaria», Desafíos, vol. 24, núm. I, pp. 175-229.

82 Imprenta Nacional (2019), Gaceta del Congreso, año XXVIII, núm. 870, pp. 29-31 
este número. La aprobación de este proyecto permitió aprobar fue la ley $\mathrm{N}^{\circ} 1955$ de 2019, que contiene el Plan nacional de desarrollo 2018-2022 $2^{83}$.

Aunque la información sobre los números de los proyectos de ley que debieron aprobarse en cada Cámara para poder expedir las leyes aparece en internet ${ }^{84}$, la manera como son publicadas las votaciones le dificulta a los ciudadanos conocer como están votando los Representantes, para así poder constatar si su confianza ha sido o no traicionada y si se votó o no los proyectos de ley de una manera diferente a la que se prometió en campaña. De esta forma, se dificulta entonces para los ciudadanos saber si en las próximas elecciones deben castigar a sus Representantes negándoles la reelección ${ }^{85}$. Sin embargo, el hecho de conocer fácilmente como están votando los representantes los diferentes proyectos de ley, no garantiza necesariamente que los ciudadanos vallan a interesarse por informarse y castigar a los Representantes en los cuales ya no confían, puesto que existe un gran desconocimiento por parte de los ciudadanos de los mecanismos de control político y de sus derechos ${ }^{86}$.

La segunda gran dificultad se presenta debido a la manera como los varias veces modificados artículos 262 y 263 de la Constitución organizaron las elecciones de los cuerpos colegiados, puesto que hicieron muy difícil que los electores puedan sancionar a un candidato por el incumplimiento de sus promesas de campaña. Esto se debe, a que según la manera como están organizadas en Colombia las elecciones para los cuerpos colegiados de elección popular es imposible votar por un candidato, puesto que sólo se puede votar por partidos políticos.

Pensemos en este ejemplo para las elecciones de un cuerpo colegiado de seis miembros. El partido AA presentó una lista con seis candidatos, en la cual se encuentra en el puesto cuarto el Candidato 4, por el cual el ciudadano CC quería votar. O, que luego de la reorganización por el voto preferente ${ }^{87}$ el candidato quedó en el cuarto

83 La situación en Colombia dista mucho la situación existente, por ejemplo, en Francia, en donde se pública de una manera muy entendible la votación de cada uno de los proyectos de ley en las Cámaras legislativas. Ver: Assemblée nationale (2020), Analyse du scrutin $n^{\circ} 2758$, Première séance du 17/06/2020. Scrutin public sur l'ensemble du projet de loi organisant la sortie de l'état d'urgence sanitaire (première lecture), en http://www2.assemblee-nationale.fr/scrutins/detail/(legislature)/15/ (num)/2758

84 Ver, por ejemplo, respecto a la ley $N^{\circ} 1955$ de 2019: Senado de la República (2019), Por la cual se expide el plan nacional de desarrollo 2018-2022. Pacto por Colombia, pacto por la equidad, http://leyes.senado.gov.co/proyectos/index.php/proyectos-ley/cuatrenio-2018-2022/2018-2019/article/227-por-la-cual-se-expide-el-plan-nacional-de-desarrollo-2018-2022-pacto-por-colombia-pactopor-la-equidad en: [13 de junio de 2020].

85 La transparencia en la información «le proporciona a los electores la facultad de obrar con conocimiento de causa. En ese sentido, no es un control ni un límite sino un elemento facilitador del gobierno democrático «. Aguilar, J. (2015), Transparencia y democracia. Claves para un concierto. México, INAI p. 30

86 Isaza, C. (2015), «El diseño institucional para la rendición de cuentas. Una valoración del caso colombiano», Gestión y política publica, vol. XXIV, núm. 2, p. 349

${ }^{87}$ El voto preferente es una de las formas de organización de las listas que pueden libremente utilizar los partidos. Según el artículo 262 de la Constitución colombiana, en el caso en que se utilice

(C) UNED. Revista de Derecho Politico

N. ${ }^{\circ} 111$, mayo-agosto 2021, págs. 315-342 
lugar. Pensemos también en que la cifra repartidora ${ }^{88}$ para la escogencia de los elegidos fue 100 votos, pero que el partido solo obtuvo 300 votos (Ver: Gráfica).

Grafica de ejemplo de unas elecciones de un cuerpo colegiado en Colombia

Lista del partido político AA

\begin{tabular}{|c|c|}
\hline Candidato 1 & Candidatos \\
\hline Candidato 2 & $\Longrightarrow$ que fueron elegidos \\
\hline Candidato 3 & \\
\hline Candidato 4 & $\Rightarrow$ Candidato por \\
\hline Candidato 5 & el cual el \\
\hline Candidato 6 & ciudadano CC votó \\
\hline
\end{tabular}

Supuestos: La cifra repartidora fue de 100 votos y el partido solo tuvo 300 votos

En este ejemplo, el voto que depositó el ciudadano CC a favor del Candidato 4, no se pierde, puesto que le sirve a otro de los candidatos de la lista ¿pero a cuál de los tres primeros candidatos de la lista le sirve para lograr su curul? Entonces, luego ¿a cuál de los tres primeros candidatos de la lista debe castigar el ciudadano negándole la reelección, si ni siquiera votó por él en un principio? Peor aún, en el hipotético caso que la misma lista hubiera obtenido mas bien 500 votos ¿cómo puede el ciudadano CC estar seguro de que su voto le sirvió al candidato 4?

Este ejemplo muestra la complicada situación en la que se encuentran los electores en Colombia, puesto que si en ningún caso pueden estar seguros de a quien de los miembros de la lista del partido por el cual votan beneficia el voto de cada elector ¿cómo pueden saber a quien deben castigar no votando por él en las próximas elecciones? En este sistema si bien «los electores tienen en principio la posibilidad de que el partido al que votan rinda cuentas por su desempeño, no es realista pensar que puedan exigir responsabilidad a los legisladores en forma individual» ${ }^{89}$. Toda vez que en este sistema «los electores no tienen la oportunidad de determinar la identidad de las personas que

esta forma, la lista no tiene un orden predefinido, puesto que esta «se reordenará de acuerdo con la cantidad de votos obtenidos por cada uno de los candidatos».

88 La cifra repartidora es el número que según el cálculo definido en el artículo 263 de la Constitución sirve para identificar cuantos candidatos fueron elegidos por cada una de las listas presentadas por los partidos.

89 Payne, M. (2006), «Sistemas de elección legislativa y gobernabilidad democrática», en Payne, M. et al, La política importa. Democracia y desarrollo en América Latina, Washington, Banco Interamericano de Desarrollo, p. 44. Esta es una consecuencia común que se genera en muchos sistemas de representación proporcional, como el colombiano, en los cuales «el nexo entre el elector y sus representantes es más débil y distante». Ibídem, p. 43 
los van a representar, no existe un representante claramente identificado con su distrito, ciudad o localidad y, por lo tanto, tampoco tienen la posibilidad de rechazarlo cuando consideran que no está ejerciendo su cargo de manera adecuada ${ }^{90}$.

Lo anterior demuestra que, aunque se cree estar votando por un candidato en Colombia, en realidad por el sistema de listas existente, se vota es por partidos. Por lo cual, la única opción que tienen los electores para sancionar a los Representantes por su mala representación es dejar de votar por la lista entera por la que votó en las elecciones precedentes y por la cual busca su reelección.

Las dificultades que en Colombia generan la manera como se publican las votaciones de los miembros de las Cámaras legislativas y la imposibilidad de conocer precisamente a quien beneficia los votos de los electores, hace muy difícil que sea una realidad el mandato del último inciso del artículo 133 de la Constitución, que afirma que «el elegido es responsable políticamente ante la sociedad y frente a sus electores del cumplimiento de las obligaciones propias de su investidura». Toda vez que la manera como fue reglamentada esta disposición no da a los electores las herramientas suficientes para que en la práctica puedan hacer responsables a sus Representantes por su mala representación ${ }^{91}$. Con lo cual, en Colombia la reglamentación de las elecciones de los Representantes a los cuerpos colegiados no redunda «en la imposición de sanciones contra los funcionarios que abusen de su poder y, por el contrario, [alimenta] la frustración, el cinismo y la apatía de los ciudadanos» ${ }^{92}$.

Esta situación es bastante preocupante, porque tal como lo demostró Moreno, Crisp y Shugart, no se puede esperar que los mecanismos horizontales por si solos logren controlar a los Representantes, toda vez que estos mecanismos solo pueden producir resultados eficaces cuando la manera como está reglamentada la responsabilidad vertical entre los Representantes y sus electores obligan a los primeros a tener en cuenta los intereses de los segundos y no sus propios intereses ${ }^{93}$.

90 Reynold, A. y Reilly B. (1997), The international IDEA handbook of electoral system design, Estocolmo, International institute for democracy and electoral assistance, p. 83

91 La situación colombiana coincide con las dificultades identificadas por varios autores internacionales, quienes han afirmado que «algunos elementos del diseño institucional tradicional contribuyen a obstaculizar la facultad de los ciudadanos de responsabilizar a sus representantes, como ser: a) la coalición de partidos o gobiernos pluralistas que diluyen la atribución de responsabilidad personal; b) los límites constitucionales establecidos para la reelección de un representante en el cargo, eliminan esa motivación en el representante». Vercellone, A. (2013). Representación y responsabilidad en la teoría de democracia deliberativa, Revista de la Facultad, vol. IV, núm. 1, Nueva Serie II, p. 289. Ver también: Przeworski, A. (1998), «Democracia y representación»..., cit, p. 15-16 y Bingham Powell, G. (2005), «Calidad de la democracia: reciprocidad y responsabilidad», Metapolítica, vol. 8, núm. 39, pp. 77-86

92 Carrillo, F. (2006), «Instituciones democráticas de rendición de cuentas en América Latina: diseño legal y desempeño real», en Payne, M. et al, La política importa. Democracia y desarrollo en América Latina, Washington, Banco Interamericano de Desarrollo, p. 133

93 Moreno, E., Crisp, B. y Shugart, M. (2003), «The Accountability Deficit in Latin America»..., cit, p. 118. De hecho, la creación de mecanismos horizontales de control «sin la reparación de las falencias de la responsabilidad vertical de los legisladores solo logra crea en los ciudadanos unas expectativas que tienen pocas esperanzas de cumplirse». Ibídem, p. 118.

(C) UNED. Revista de Derecho Politico

N.o 111, mayo-agosto 2021, págs. 315-342 


\section{CONCLUSIÓN}

Los Estados modernos, y entre ellos Colombia, aunque suelen calificarse como democracias representativas, funcionan de la manera como se idearon los Regímenes Representativos. De esta forma, son las condiciones de este Régimen las que definen las obligaciones que actualmente tienen los Representantes respecto a sus electores. En los Regímenes Representativos los Representantes no tienen la obligación jurídica de votar los proyectos de ley como lo quieren sus electores o como lo prometieron en su campaña, puesto que "para el Representante no existe ninguna subordinación hacia los ciudadanos, pues [... no es] respecto de éstos, ni responsable, ni revocable, ni obligado a rendir cuentas» ${ }^{94}$.

El único lazo que une a los Representantes con sus electores es una incierta responsabilidad política que se configura por la necesidad de los Representantes de renovar su mandato cada cierto tiempo. Esta incierta responsabilidad política ha permitido a los electores de los principales Estados occidentales del mundo construir buenos gobiernos que protegen y satisfacen los derechos de sus ciudadanos. Sin embargo, para que esta responsabilidad se pueda configurar, es necesario que como mínimo, en la práctica existan las condiciones adecuadas para que los electores puedan conocer fácilmente la manera como sus Representantes están votando cada uno de los proyectos de ley y que puedan sancionarlos al momento de la reelección negándoles su voto.

Esta es una de las grandes dificultades que tiene el Régimen Representativo en Colombia, puesto que la manera como están reglamentadas las elecciones para las Cámaras legislativas y la manera como se publican el sentido en el que vota cada Representante hacen muy difícil que en la práctica los electores colombianos puedan hacer responsables a sus Representantes por su mala representación.

Es necesaria la corrección de estas dificultades en Colombia, puesto que el gran distanciamiento que existe entre los Representantes y la voluntad real de sus electores está dejando al pueblo sin ninguna otra opción diferente a la protesta social para que sus intereses sean escuchados y sus demandas satisfechas.

94 Carre de Malberg, R. (2001), Teoría general del Estado..., cit, p. 940 
Title

The responsibility of representatives in from of their electors in Colombia

\title{
Summary:
}

Introduction. I. THE RESPONSIBILITY OF REPRESENTATIVES IN REPRESENTATIVE REGIMES. A. The appearance of the Representative Regime. B. The obligations of the Representatives in the Representative Regime. II. THE OBLIGATIONS OF REPRESENTATIVES IN COLOMBIA. A. The Representative Regime in Colombia. B. Reduced control over the Representatives in Colombia. CONCLUSION. BIBLIOGRAPHY.

\section{Resumen}

Los principales Estados occidentales del mundo adoptaron una forma de gobierno conocida inicialmente como el «Régimen representativo», para proteger y satisfacer los derechos de sus ciudadanos, permitiéndole a los electores hacer responsables a sus Representantes por las malas decisiones que toman, a través de la reelección periódica. En aquellos Estados, el Régimen representativo ha logrado en buena parte su propósito. Sin embargo, el estudio de la responsabilidad de los Representantes frente a sus electores en Colombia, realizado a través de una metodología analítico-descriptiva, permitió identificar que la manera como está reglamentado en concreto el Régimen representativo en este país, dificulta en la práctica que los electores puedan hacer responsables a sus Representantes por su mala representación.

\begin{abstract}
The main western states of the world have adopted a form of government initially known as the «Representative Regime» to protect and satisfy the rights of their citizens. It allows voters to hold their representatives accountable for the bad decisions they make, through periodic reelection. In those States, the Representative Regime has largely achieved its purpose. However, in Colombia, the study of the responsibility of the Representatives towards their voters, carried out through an analyticaldescriptive methodology, allowed us to identify that the way in which the representative Regime is specifically regulated in this country, makes it difficult in practice for voters to hold their representatives accountable for their misrepresentation.
\end{abstract}

Palabras clave

Régimen Representativo; Democracia; Mandato imperativo; Revocatoria de mandato.

\section{Keywords}

Representative Regime; Democracy; Mandatory Mandate; Revocation of mandate.

N. o 111, mayo-agosto 2021, págs. 315-342 
